\title{
Simulation of Complex Hydraulic Fracture Generation in Reservoir Stimulation
}

\author{
Zhennan Zhang ${ }^{1 *}$, Shujun Peng ${ }^{1}$, Ahmad Ghassemi² ${ }^{2}$ Xiurun $\mathrm{Ge}^{1}$ \\ ${ }^{1}$ School of Naval Architecture, Ocean and Civil Engineering, Shanghai Jiao Tong University, \\ Shanghai, 200240, China \\ ${ }^{2}$ Mewbourne School of Petroleum and Geological Engineering, The University of Oklahoma, \\ Norman, OK 73091, USA
}

\begin{abstract}
:
In unconventional petroleum and geothermal reservoirs, a complex fracture network is mostly desired in order to enhance the reservoir permeability. In this paper, the mechanism of hydraulic fracture branching and generation of a cluster of fractures is investigated via numerical simulation. Firstly, the reservoir rock is modeled using lattice cell version of the discretized virtual internal bond method. An algorithm is developed to identify the hydraulic fracture trajectory. A sensitivity study is conducted with different pressurization rates, fluid pressures, in-situ stresses and orientations of perforations. It is found that a high fluid pressure and a high pumping rate are the necessary and sufficient conditions, respectively for creating fracture branching and clusters. The pressurization rate plays a critical role in branching fracture, but the role it plays is subjected to its duration as fracture propagates. The fluid pressure, as a controlling factor that integratively accounts for the effects of pressurization rate and duration, determines the degree of fracture branching. The location of fracture network is controllable by adjusting the magnitude of fluid pressure. The direction of propagation and distribution of fractures are determined by the in-situ stress contrast. As the contrast in the in-situ stresses increases, the branched fractures increasingly tend to propagate along the maximum in-situ stress direction. As expected, the effect of perforation direction on fracture growth is local; with hydraulic fracture advancing forward, it gradually turns to and propagates along the maximum in-situ direction. The degree of contrast between the in-situ stresses determines how fast the hydraulic fracture turns to the maximum in-situ stress direction. The simulation study helps to understand the mechanism and dynamics of complex hydraulic fracture generation in unconventional reservoirs.
\end{abstract}

Keywords: Hydraulic fracture; Pressure pulse; Pressurization rate; Shale gas; Fracture network; Lattice model

\section{Introduction}

Hydraulic fracturing technique is used to stimulate the oil, gas and geothermal. To increase the permeability of the stimulated reservoir volume, it is desirable to create fracture clusters and networks. Fracture branching and formation of multiple fractures help to develop a complex fracture network. Fracture branching is a kind of unstable behavior related to the dynamics of fracture propagation. According to the classical dynamic fracture theory, the fracture does not

${ }^{*}$ Corresponding author. Tel./fax: +862134204346.

Email address: zhennanzhang@ sjtu.edu.cn (Z. Zhang) 
branch until the speed of fracture propagation reaches a critical value. Therefore, the generation of branching fractures need to be studied as a dynamic fracture problem rather than a quasi-static one. There exists a vast of literatures focused on the simulation of quasi-static HF propagation, but with a few on the dynamic HF, let alone how to generate complex HF network. Zhao et al. (2013) holds that an unusually high pumping rate is required to make available a high fluid pressure at the freshly grown fracture tip area and initiate branching. This is the necessary condition, but in order to prevent the dissipation of the high fluid pressure through leak-off, the pumping must be sustained at a high rate as well. This is the sufficient condition, without which the branching cannot progress. Under such conditions, the fracturing process is no longer a quasi-static one, but dynamic.

The high pumping rate causes the fluid pressure to rise to a very high level in a very short time. Such high pressurization rate can generate different fracturing patterns to the quasi-static one. To initiate and propagate multiple radial fractures from the wellbore, several pressure pulse stimulation techniques have been developed, for example, the propellant fracturing technique, the pulsed power technique (Gray et al., 1987; Mao et al., 2012), the chemically-induced pressure pulse technique (Al-Nakhli, 2015). The multiple-fracturing pattern is not achievable by the quasi-static loading scheme, but by a pressure pulse with high pressurization rate. The researches by (Schmidt et al., 1980; Swift and Kusubov, 1981, 1982; Cuderman, 1986; Yang et al., 2000) demonstrated that the pressurization rate ( or loading rate) is a critical factor in determining the fracturing type: the explosive, the multiple or the hydraulic fracturing. Yang et al. (2000) found that there exists a rock strength-related transition pressurization rate from the hydraulic- to the multiple-fracturing pattern through experiment. So, the design of the controlled pulse fracturing technique should be based on better understanding the response of HF to the pressurization rate (Fourney, 1983; Hunt III and Shu, 1989). Besides the pressurization rate, the poroelasticity, the permeability of rock formation, the initial environment around the borehole(water-filled or dry) (Swift and Kusubov, 1981,1982) and the in-situ stresses have also influence on the dynamic response of HF. Nilson et al. (1985) and Safari et al. (2014) considered the effect of rock permeability and pore pressure in their works, respectively. The induced-fracture potential of a rock is actually not a rock property, but a complex function of stress state, loading conditions and strength properties, suggested as Safari et al. (2015).

The pressure pulse-driven fracture technique is more focused on the generation of multiple radial fractures from the wellbore. However, the creation of fracture network is more dependent on the fracture branching and connecting with the natural fractures in large scale field. In this paper, we will use numerical simulation method to explore the dynamic aspect of hydraulic fracturing process, leading to branching, cluster and potentially network formation. We begin the workflow with Zhang's (2013) approach to model the rock matrix with discretized virtual internal bond and develop an algorithm to apply the internal fluid pressure to the newly-created fracture faces. We conduct parametric study to explore fracture propagation and branching behaviors under different conditions. 


\section{Mechanical modeling of rock material}

\subsection{Choice of lattice model}

The lattice model is more suitable for studying dynamic fracture propagation, compared to the classical continuum mechanics, which is not easily amenable to dynamic fracture simulation study. Conventional lattice model also required an advanced feature in order to simulate fracture propagation, at a mesoscale, along the mineral grain boundaries. Zhang (2013) and Zhang and Chen (2014) introduced the interatomic potential into the lattice model and developed the discretized virtual internal bond (DVIB) method. The DVIB is different from the conventional lattice method in that its discrete structure consists of unit bond cells. The bond cell can take any geometry with any number of bonds. DVIB is thus suitable for modeling rock that consists of mineral grains on the mesoscale. In addition, the DVIB adopts the hyperelastic potential to describe the bond, so it can account for the hyperelasticity of material at crack tip. This is critically important for dynamic fracture simulation according to Buehler et al. (2003) and Buehler and Gao (2006). So, in this study, we will use the DVIB to model rock and study the dynamic fracture propagation.

\subsection{Scheme for DVIB}

The constitution of DVIB is shown as Fig.1, which represents a continuum with a discrete bond system. The discrete structure is composed of unit bond cells. The total energy of the discrete structure is indentified as

$$
W=\sum W_{\text {cell }}
$$

where $W$ is the total energy; $W_{\text {cell }}$ is the unit cell energy, $W_{\text {cell }}=\sum_{b=1}^{N} \Phi_{b}$ with $\Phi_{b}$ being the energy of the $b^{\text {th }}$ bond and $N$ being the total bond number of a unit cell. The relationship between the bond and the particle number of a unit cell is $N=q(q-1) / 2$ where $q$ is the particle number of a unit cell.

The total energy of the discrete system is a function of the particle displacements. Based on the principle of minimum energy, the particle force vector and the stiffness matrix are respectively derived as

$$
F_{i}=\frac{\partial W}{\partial u_{i}}, \quad K_{i j}=\frac{\partial^{2} W}{\partial u_{i} \partial u_{j}}
$$

where $F_{i}, K_{i j}$ are respectively the component of the particle force and the stiffness matrix of the discrete system; $u_{i}$ denotes the component of the particle displacement array.

The scheme for transforming the rock into the discrete structure of DVIB is shown in Fig.2. A 
mineral grain is modeled as a discrete unit bond cell. Many unit bond cells are composed together to form the entire structure of a rock through the common particles along the cell boundary. In a unit bond cell, each bond is characterized by the potential $\Phi_{I J}(1)$ with subscript $I, J$ being the particle indices. Its first derivative with respect to bond deformation is

$$
\Phi_{I J}^{\prime}(1)=\left\{\begin{array}{ccc}
A\left(1-1_{0}\right) \cdot \exp \left(-\left(1-1_{0}\right) / B\right) & \text { if } & 1>1_{0} \\
A\left(1-1_{0}\right) & \text { if } & 1 \leq 1_{0}
\end{array}\right.
$$

where $1_{0}$ is the undefomred bond length, $\Phi_{I J}^{\prime}\left(1_{0}\right)=0 ; A, B$ are the micro bond parameters,

$A$ is given by the following Eq.(6) and $B=\varepsilon_{t} 1_{0}$ with $\varepsilon_{t}$ being the strain value at the peak stress of the uniaxial tensile stress-strain curve.

The force-displacement of a unit cell is derived as

$$
F_{i}=\frac{\partial}{\partial u_{i}}\left(\sum_{I<J} \Phi_{I J}(1)\right)=\sum_{I<J} \frac{\partial \Phi_{I J}(1)}{\partial u_{i}}=\sum_{I<J}\left(\Phi_{I J}^{\prime}(1) \cdot \frac{\partial \mathrm{l}}{\partial u_{i}}\right)
$$

and the stiffness matrix is

$$
\begin{aligned}
K_{i j} & =\frac{\partial^{2}}{\partial u_{i} \partial u_{j}}\left(\sum_{I<J} \Phi_{I J}(1)\right)=\sum_{I<J} \frac{\partial^{2} \Phi_{I J}(1)}{\partial u_{i} \partial u_{j}} \\
& =\sum_{I<J}\left[\Phi_{I J}^{\prime \prime}(1) \cdot \frac{\partial \mathrm{l}}{\partial u_{i}} \cdot \frac{\partial \mathrm{l}}{\partial u_{j}}+\Phi_{I J}^{\prime}(1) \cdot \frac{\partial^{2} 1}{\partial u_{i} \partial u_{j}}\right]
\end{aligned}
$$

The bond parameters are calibrated as (Zhang, 2013)

$$
A=\Phi_{I J}^{\prime \prime}\left(1_{0}\right)=\gamma \cdot \frac{E V}{\Omega 1_{0}^{2}}
$$

where $\gamma$ is a coefficient, $\gamma=6$ for $3 \mathrm{D}$ cases, $\gamma=3$ for plane stress cases and $\gamma=16 / 5$ for plane strain cases.

\section{Scheme for applying fluid pressure}

As the main hydraulic fracture propagates, the boundary condition of fluid pressure needed on the newly-created fracture faces must be applied and updated as time progresses. First we need to identify the newly-created fracture facet at each time step. The lattice model with DVIB referred to above does not include explicit fracture propagation criterion, we propose an identification method for the creation of a new fracture facet through the deformation of a unit cell. According to (Liao et al., 1997), the equivalent strain of a unit cell can be calculated as 


$$
\begin{aligned}
& \varepsilon_{i j}=\frac{1}{V} \sum_{c} \Delta_{i}^{c} f_{n}^{c} Q_{j n} \\
& Q_{j n}=\left[\frac{1}{V} \sum_{c} f_{j}^{c} f_{n}^{c}\right]^{-1}
\end{aligned}
$$

where $f_{i}^{c}, \Delta_{i}^{c}$ are the $c^{\text {th }}$ bond vector and deformation vector in a unit cell, respectively; $Q_{j n}$ is the fabric tensor.

When the unit cell strain meets the following condition, a crack facet is assumed to be created in this unit cell.

$$
\varepsilon_{1}>\gamma \varepsilon_{t}
$$

where $\varepsilon_{1}$ is the first principal value of strain tensor; $\gamma$ is a coefficient greater than unity. Here we assume 2.0.

The newly-created crack facet is perpendicular to the first principal direction of strain tensor, shown as Fig.3a. To facilitate the application of fluid pressure, we directly impose the fluid pressure on the inner boundary of this unit cell, shown as Fig.3b. The equivalent particle force for a given line segment of the unit cell boundary is computed as

$$
\begin{aligned}
& F_{1 x}=F_{2 x}=n_{1} P L / 2 \\
& F_{1 y}=F_{2 y}=n_{2} P L / 2
\end{aligned}
$$

\section{Analysis on hydraulic fracture cluster creation}

We simulate the hydraulic fracture propagation under different conditions, using a $(100 \mathrm{~cm} \times$ $100 \mathrm{~cm}$ ) square domain with a centered round hole, representing the wellbore. The domain is subjected to the far-field in-situ stresses, $\sigma_{H}$ and $\sigma_{h}$, as shown in Fig.4a. Triangular cell is used to discretize the domain(Fig.4b), with 40,670 cells and 20,543 particles. The material properties for the base case are: Young's modulus $E=2.16 \mathrm{GPa} ; \varepsilon_{t}=3.34 \times 10^{-3}$. To check the uniaxial tensile response of material modeled by DVIB with the parameter $E=2.16 \mathrm{GPa}$ and $\varepsilon_{t}=3.34 \times 10^{-3}$, we simulate a uniaxial tension case by DVIB. The simulated result is shown in Fig.5, indicating that the uniaxial tensile strength is about $\sigma_{b}=3.1 \mathrm{MPa}$.

In this study, the rock formation is assumed to be impermeable and the fluid is incompressible. The fluid pressure is uniformly distributed along the fracture faces. At the beginning of simulation, we gradually apply the in-situ stresses in advance. When the in-situ stresses reach the prescribed values, we allow the stress to relax over several time steps under the constant in-situ stress condition, then we impose the fluid pressure on the inner boundary of wellbore at a given rate. Two loading schemes are applied to the fluid pressure. Shown in Fig.6, in 
the Loading Scheme I, the fluid pressure is applied with a constant pressurization rate while in the

Loading Scheme II, the fluid pressure is kept constant when it reaches a certain pressure level at a given pressurization rate.

\subsection{Validation Example}

To validate the model, we compare numerical results with data shown in Yang et al. (2000) who have conducted a series of experiment to study the transition pressurization rate from the hydraulic- to the multiple-fracture. The material parameters provided in (Yang et al., 2000) are: Young's modulus $E=2.16 \mathrm{GPa}$ and uniaxial tensile strength $\sigma_{b}=3.61 \mathrm{MPa}$. The DVIB model with the parameter input ( $E=2.16 \mathrm{GPa} ; \varepsilon_{t}=3.34 \times 10^{-3}$ ) can basically represent the response of this experiment material. The pressurization rate indicated in the Figure 6a of (Yang et al., 2000) is about $R=22.7 \mathrm{MPa} / \mathrm{ms}$. So, we use it in this example. Take the Loading Scheme I(Fig.6) for the fluid pressure where the fluid pressure level is not limited. Following the boundary conditions of experiment, we set $\sigma_{H}=\sigma_{h}=0$.

To ensure that fractures can initiate at certain points along the wellbore, we introduce the heterogeneity into the specimen. We assume that the modulus of unit cells are random numbers, complying with the Weibull distribution law

$$
f(E)=\frac{m}{\overline{\mathrm{E}}}\left(\frac{E}{\overline{\mathrm{E}}}\right)^{m-1} \exp \left[-\left(\frac{E}{\overline{\mathrm{E}}}\right)^{m}\right]
$$

where $\overline{\mathrm{E}}$ is the mean value of Young's modulus $E ; m$ is the homogeneity index. A higher $m$ indicates a more homogenous material. In this simulation, we take $m=10$ and $m=100$ in different cases. The corresponding Young's modulus distributions are shown in Fig.7a and the grey image with $m=10$ is shown in Fig.7b.

The comparison between the experimental observation in (Yang et al., 2000) and the simulation results are shown in Fig.8. Fig.8a clearly shows that there are four main fractures created in the experiment. In the numerical simulation, when we take the pressurization rate $R=22.7 \mathrm{MPa} / \mathrm{ms}$, there are four main fractures and two secondary fractures initiated along the wellbore. They propagate radially outward as shown as Fig.8b. To examine the multiple-fracture results from the dynamic loading effect or from the heterogeneity, we increase the homogeneity index to $m=100$ which is almost the homogenous material indicated as Fig.7a and re-simulate this case. There are still four main radial fractures initiated. The included angles between the main fractures are almost the same, shown as Fig.8c. So, we can conclude that the four main fractures do result from the dynamic loading effect rather than the heterogeneity. Both the number and the arrangement of the created main fractures agree with the experimental observation(Fig.8a) in (Yang et al., 2000).

According to the prediction of (Yang et al., 2000), once the pressurization rate exceeds the 
transition point from a hydraulic- to multiple-fractures, the number of the created fractures increases with the pressurization rate. To examine whether our method can reproduce this phenomenon, we double the pressurization rate, namely $R=45.4 \mathrm{MPa} / \mathrm{ms}$, and simulate this case. We find that there are six main radial fractures created in both the case $m=10$ and $m=100$, respectively shown in Fig.8d and Fig.8e.

Why does a high pressurization rate induce multiple fractures? Zhang et al.(1999) suggested that the rock specimen can break into several fragments rather than only two halves at very high loading rates. The physical essence of this phenomenon is the same as the initiation of multiple fractures along wellbore at high pressurization rate. As for the underlying physical mechanism, it is still unclear. The breakthroughs might be found from the strain rate effect.

Besides multiple-fracture initiation, we also note that the main radial fractures branch after they grow to a certain length in Fig.8. The branching is an unstable manner of fracture propagation. Ozbolt et al. $(2011,2013,2015)$ attributed crack branching to the inertia at crack tip. It is held that the inertia force at crack tip resists the crack to propagate along its original pathway and splits it into two new cracks, resulting in branching. This is an explanation of crack branching from the stand point of resistance force. What is underlying reason from the stand point of energy dissipation? Likely, more energy is supplied to the system than needed for stable propagation so that multiple surfaces are necessary.

If we take the critical fluid pressure at which fracture initiates as the breakdown pressure, the breakdown pressure presents a strong linear correlation with the pressurization rate, shown in Fig.9, which is consistent with the conclusion of (Swift and Kusubov,1981, 1982).

The validation examples suggest that the DVIB approach can capture the response of the dynamic HF and the simulation results by this method are reliable. In the following sections, we will analyze the branching behaviors of HF subjected to dynamic load. In the following simulations, no heterogeneity is introduced into the material.

\subsection{Effects of pressurization rate}

The pressurization rate is considered as the key factor in the pressure pulsed fracturing operation. To check its effect on fracture branching, take the Loading Scheme I(Fig.6) for fluid pressure and simulate the examples with different pressurization rates $R=0.227,2.27,22.7,45.4$, 113.5 and 227.0MPa/ms, respectively. The in-situ stresses are $\sigma_{h}=2.0 \mathrm{MPa}$ and $\sigma_{H}=5.0 \mathrm{MPa}$. The simulation results are shown in Fig.10, which clearly demonstrates that the pressurization rate has a critical impact on fracturing branching. When pressurization rate is low, say $R=0.227 \mathrm{MPa} / \mathrm{ms}$, the HF propagates along the direction of maximum in-situ stress. Only when the fracture grows to near the boundary of computation domain, a minor branching phenomenon is observed (Fig.10a). When we increase the pressurization rate from $0.227 \mathrm{MPa} / \mathrm{ms}$ to $2.27 \mathrm{MPa} / \mathrm{ms}$, obvious branching behaviors are observed when the fracture grows to a certain length (Fig.10b). With further increasing the pressurization rate, the degree of branching becomes more and more 
signifcant and the fracture growth length at which branching initiates becomes shorter and shorter, shown as Fig.10c-10f. So, the pressurization rate is the necessary condition for fracture branching.

From Fig.10 we note that the duration of the pressurization rate is different in different cases. In the low pressurization rate case, e.g., $R=0.227 \mathrm{MPa} / \mathrm{s}$, the duration is $30.12 \mathrm{~ms}$ while in the high pressurization rate case, e.g., $R=227.0 \mathrm{MPa} / \mathrm{s}$, the duration is only $0.494 \mathrm{~ms}$. Fig. 11 suggests that to what extent the pressurization rate can play in branching fracture is determined by its duration. When the duration is short (Fig.11a), the fracture propagates straightforward in stable manner without branching. However, with the duration increasing, the fracture begins to branch, shown as Fig.11b-d. To consider the effect of the pressurization rate on fracture branching, the duration should be accounted together. The fluid pressure level can integratively characterize the pressurization rate and duration. In the following section, the effect of the fluid pressurve level, as a controlling factor, is discussed.

\subsection{Effects of fluid pressure level}

To explore the pressure level on the HF, we set the pressure level $P=7.0$ and 25.0MPa with pressurization rate $R=22.7$ and $135.7 \mathrm{MPa} / \mathrm{ms}$, respectively. The in-situ stresses are $\sigma_{h}=2.0 \mathrm{MPa}$ and $\sigma_{H}=5.0 \mathrm{MPa}$. Follow the Loading Scheme II shown in Fig.6 and the simulated results are shown in Fig.12. From Fig.12 it is seen that the pressure level has a critical effect on fracture branching. The degree of fracture branching in the higher pressure level (Fig.12c and Fig.12d) is much more significant than in the lower one (Fig.12a and Fig.12b). So, to what extent the pressurization rate can play on fracture branching depends on the accumulated fluid pressure level and the sustainable time. The fluid pressure cannot be accumulated to a high level with a low pressurization rate. For instance, in the case of $R=0.227 \mathrm{MPa} / \mathrm{ms}$ of Fig.10, the accumulated fluid pressure is only about $6.8 \mathrm{MPa}$ in a long time $t=30.12 \mathrm{~ms}$. However, in the case of $R=227.0 \mathrm{MPa} / \mathrm{ms}$, the fluid pressure can be accumulated to $112.1 \mathrm{MPa}$ in a short time $t=0.494 \mathrm{~ms}$. So, the level that the fluid pressure can reach is dependent on the pressurization rate. Fig.12 also confirms that it is insufficient only to consider the pressurization rate in fracture branching. The pressurization rate and the duration should be considered together.

In Fig.12, we note that the HF does not branch off until it grows to a certain length. Here, we define the HF length over which HF branches as the critical fracture length. To investigate the correlation between the critical fracture length and the fluid pressure level, we mark out the critical fracture lengths for different pressure level cases, shown in Fig.13. Fig.14 shows the relationship between the critical fracture length and the pressure level, which clearly exhibits that the critical fracture length reduces with increasing pressure level. At the same pressure level, the critical fracture length reduces with increasing pressurization rate. This suggests a significant possibility, i.e., the location of HF network initiation may be controllable by adjusting the fluid pressure level. Though the scaling law of this relation is not clear, we notice at least that the fracture branching location can be controlled by the adjusting the fluid pressure. 
In order to maintain the fluid pressure constant at a specified level, the injection rate must be adjusted as the main hydraulic fracture grows. To evaluate the variation of injection rate during dynamic HF propagation, we compute the injection rates from the time when the fluid pressure is applied. The volume of the fluid pumped into the wellbore should be equal to the increment of fracture volume plus that of wellbore, shown as Fig.15, since the rock is assumed to be impermeable and the fluid incompressible. So, the injection rate can be calculated as

$$
q=\frac{d V_{c w}}{d t}
$$

where $d V_{c w}$ is the increment of crack volume, the wellbore due to the elastic deformation and crack growth; $d t$ is the time interval.

The injection rate variations with time are shown in Fig.16. From Fig.16 it is seen that there exists a turning point in each curve. Before the turning point, the injection rate smoothly increases with time and the total increment of injection rate is very small. This indicates that the fracture propagation is still stable before the turning point. After the turning point, the injection rate increases significantly (almost sharply) with time. This indicates that the fractures propagates in unstable manner, branching extensively. So, after the turning point, a huge pumping rate is needed to sustain the fracture branching process. The higher the fluid pressure level is, the higher the injection rate is required. The pressurization rate has a significant influence on the timing of the turning point. The higher the pressurization rate is, the shorter the turning point time.

To achieve such high injection rate, the conventional pumping technique seems inadequate. The water pressure blasting technique developed by Huang et al. (2011) might provide a possible way to generate such high injection rate.

\subsection{Effects of in-situ stress contrast}

To further explore the effect of in-situ stresses, we set different in-situ stresses and simulate the HF process. The final HF patterns are shown in Fig.17. From Fig.17 we can find that when the in-situ stress difference is zero, the HF network is distributed isotropically(Fig.15a). However, with increasing the in-situ stress difference, the HF network gradually tends to distribute along the maximum in-situ stress direction, shown as Figs.17b and 17c. This demonstrates that the in-situ stress contrast dominates the distribution of HF clusters and eventually the network.

\subsection{Effects of the oriented perforations}

To study the effect of the oriented perforations on the dynamic HF behaviors, we set two symmetrical perforations connecting the wellbore, shown as Fig.18. Perforation length is $0.1 \mathrm{~m}$. The in-situ stresses are $\sigma_{h}=2.0 \mathrm{MP}$ and $\sigma_{H}=2.5 \mathrm{MPa}$. The fluid pressure is assumed to be uniformly distributed in the perforation and the wellbore. In the first case, we change the perforation inclinations, and keep the pressurization rate $R=22.7 \mathrm{MPa} / \mathrm{ms}$ and the pressure level $P=3.5 \mathrm{MPa}$. The simulation results are shown in Fig.19. For such a low fluid pressure level, the 
HF propagates in a stable manner as a quasi-static one even though the pressurization rate is as high as $R=22.7 \mathrm{MPa} / \mathrm{ms}$. No fracture branching is observed. Though the inclinations of perforation are different, the HF finally tends to propagate along the maximum in-situ stress direction. The bigger the inclination angle is, the longer the distance that they turn to the maximum in-situ stress direction. With increasing the difference of in-situ stresses, the HF turns to the maximum in-situ stress direction faster, shown as Fig.20. The simulated HF propagation tendency agrees with the experimental results reported by Jiang et al.(2009) and Zhang and Chen(2010).

However, when we increase the fluid pressure level from $P=3.5$ to 6.0 and $8.0 \mathrm{MPa}$, very obvious branching behaviors are observed, shown as Fig.21. The higher the fluid pressure is, the more the fracture branches. The branched fractures propagate along different directions (Fig.21c), but most of them propagate along the maximum in-situ stress direction. This confirms that a high fluid pressure is a necessary condition for multiple HF generation and the in-situ stress dominates the distribution of HF network as well.

\section{Conclusions}

Through a novel numerical simulation method, we have explored the process of dynamic hydraulic fracture propagation and formation of a cluster of fractures in response to branching phenomenon. Fracture branching can enhance fracture network complexity and enhance reservoir permeability. The pressurization rate has a critical impact on the number of radial fractures initiated along the wellbore and the fracture branching degree. However, the impact of pressurization rate on fracture branching is subjected to its duration. The fluid pressure level, as an integrative quantity accounting for both the pressurization and duration, determines the branching degree of fracture. The higher the fluid pressure, the more frequent denser the branching. The location of multiple fracture formation is controllable by adjusting the fluid pressure level. To sustain high fluid pressure level during fracturing process, a large pumping rate is required.

The growth direction of branched fractures is dominated by the in-situ stress contrast. The larger the in-situ stress difference, the denser the branched fractures distribution in the maximum in-situ stress direction. In the case of wellbore with oriented perforations, the HF doesn't branch under lower fluid pressures. It propagates smoothly and eventually turns to the maximum in-situ stress direction. The larger the difference of in-situ stresses, the faster the HF turns to the maximum in-situ stress direction. Under a higher fluid pressure, the HF branches and a HF cluster forms. Most branched HFs tend to propagate along the maximum in-situ stress direction.

\section{Acknowledgement}

The present work is supported by the National Natural Science Foundation of China (No. 11172172), which is gratefully acknowledged.

A. Ghassemi would like to thank the support of U.S. Department of Energy Office of Energy Efficiency and Renewable Energy under Cooperative Agreement DE-PS36-08GO1896. This support does not constitute an endorsement by the U.S. Department of Energy of the views 
expressed in this publication.

\section{References:}

Al-Nakhli, A.R., 2015. Chemically-induced pressure pulse: a new fracturing technology for unconventional reservoirs. SPE Middle East Oil \& Gas Show and Conference, 8-11 March, Manama, Bahrain. SPE-172551-MS. Doi: http://dx.doi.org/10.2118/172551-MS.

Buehler, M.J., Abraham, F.F., Gao, H., 2003. Hyperelasticity governs dynamic fracture at a critical length scale. Nature 426, 141-146.

Buehler, M.J., Gao, H., 2006. Dynamical fracture instabilities due to local hyperelasticity at crack tips. Nature 439, 307-310.

Cuderman, J.F., 1986. Effects of well-bore liquids in propellant-based fracturing. 27th U.S. Symposium on Rock Mechanics, Tuscaloosa, AL, USA, June 23-25. ARMA-86-0562.

Fourney, W.L., 1983. Gas well stimulation studies. In: Rock Fracture Mechanics, Volume 275 of the series International Centre for Mechanical Sciences, pp 353-369.

Gray, E.W., Moeny, W.M., Beckes, B.R., Davis, B.B., 1987. Pulsed power fracturing of rock, Proceedings of 6th IEEE Pulsed Power Conference, pp. 330-335. Doi: http://dx.doi.org/10.2118/153805-MS.

Huang, B., Liu, C. H., Fu, J., Guan, H., 2011. Hydraulic fracturing after water pressure control blasting for increased fracturing. Int. J. Rock Mech. Min. Sci. 48, 976-983.

Hunt III, W.C., Shu, W.R., 1989. Controlled pulse fracturing for well stimulation. Presented at the SPE Joint Rockly Mountain Regional/Low Permeability Reservoirs Symposium and Exhibition, 6-8 March, Denver, Colorado. SPE-18972-MS. DOI: http: //dx.doi.org/10.2118/18972-MS.

Jiang, H., Chen, M., Zhang, G.Q., Jin, Y., Zhao, Z.F., Zhu, G.F., 2009. Impact of orientation perforation on hydraulic fracture initiation and propagation. Chinese J. Rock Mech. Eng. 28(7), 1321-1326 (In Chinese).

Liao, C. L., Chang, T.P., Young, D.H., Chang, C.S., 1997. Stress-strain relationship for granular materials based on the hypothesis of best fit. Int. J. Solids Struct. 34(31-32), 4087-4100.

Mao, R.H., De Pater, H., Leon, J.F., Fram, J., Storslett, S., Ewy, R., Stefani, J., 2012. Experiments on pulse power fracturing. Presented at the SPE Western Regional Meeting, 21-23 March, Bakersfield, California, USA . SPE153805 . Doi: http://dx.doi.org/10.2118/153805-MS

Nilson, R.H., Proffer, W.J., Duff, R.E., 1985. Modelling of gas-driven fractures induced by propellant combustion within a borehole. International Journal of Rock Mechanics and Mining Sciences \& Geomechanics Abstracts, 22(1): 3-19.

Ozbolt, J., Sharma, A., Reinhardt, H., 2011. Dynamic fracture of concrete - compact tension specimen. Int. J. Solids Struct. 48, 1534-1543.

Ozbolt, J., Bosnjak, J., Sola, E., 2013. Dynamic fracture of concrete compact tension specimen: Experimental and numerical study. Int. J. Solids Struct. 50, 4270-4278

Ozbolt, J., Bede, N., Sharma, A., Mayer, U., 2015. Dynamic fracture of concrete L-specimen: 
Experimental and numerical study. Eng. Fract. Mech. 148, 27-41.

Safari, R., J. Huang, U. Mutlu. 2014. 3D Analysis and Engineering Design of Pulsed Fracturing in Shale Gas Reservoirs. Presented at 48th US Rock Mechanics/Geomechanics Symposium, Minneapolis, MN, USA, 1-4 June, 2014. ARMA 14-7014.

Safari, R., Gandikota, R., Mutlu, O., Ji, M., Glanville, J., Abass, H., 2015. Pulse fracturing in shale reservoirs: Geomechanical aspects, ductile/Brittle transition, and field implications. SPE168759. SPE Journal. DOI: http://dx.doi.org/10.2118/168759-PA

Schmidt, R.A., Warpinski, N.R., Cooper, P.W., 1980. In situ evaluation of several tailored-pulse well-shooting concepts. Presented at the SPE/DOE Symposium on Unconventional Gas Recovery held in Pittsburgh, Pennsylvania, May 18-21, 1980. SPE/DOE 8934. DOI: http://dx.doi.org/10.2118/8934-MS.

Swift, R.P., Kusubov, A.S., 1981. Tailored-pulse loading conditions for multiple fracturing of boreholes. The 22nd U.S. Symposium on Rock Mechanics (USRMS), 29 June-2 July, Cambridge, Massachusetts. ARMA-81-0231.

Swift, R.P., Kusubov, A.S., 1982. Multiple fracturing of boreholes by using tailored-pulse loading. Society of Petroleum Engineers Journal, 22(6): 923-932. SPE-9892-PA. DOI: http://dx.doi.org/10.2118/9892-PA.

Yang, D.W., Risnes, R., 2000. Experimental study on fracture initiation by pressure pulses. Proceedings - SPE Annual Technical Conference and Exhibition, p 259-272. Presented at the SPE Annual Technical Conference and Exhibition held in Dallas, Texas, 1-4 October, 2000. SPE63035. Doi: http://dx.doi.org/10.2118/63035-MS.

Zhang, Z., 2013. Discretized virtual internal bond model for nonlinear elasticity. Int. J. Solids Struct. 50(22-23), 3618-3625.

Zhang, G., Chen, M., 2010. Dynamic fracture propagation in hydraulic re-fracturing. J. Pet. Sci. Eng. 70, 266-272.

Zhang, Z., Chen, Y., 2014. Modeling nonlinear elastic solid with correlated lattice bond cell for dynamic fracture simulation. Comput. Methods Appl. Mech. Engng. 279, 325-347.

Zhao, H., Hang, C., Liu, G., Li, Y., Shi, J., Ren, P., 2013. New insight into mechanisms of fracture network generation in shale gas reservoir. J. Pet. Sci. Eng. 110, 193-198.

Zhang, Z.X., Kou, S.Q., Yu, J., Yu, Y., Jiang, L.G., Lindqvist, P.A., 1999. Effects of loading rate on rock fracture. Int. J. Rock Mech. Min. Sci. 36, 597-611. 


\section{Figure Captions}

Fig.1 Constitution of DVIB discrete structure

Fig.2 Modelling rock formation with DVIB (a) mesostructure of rock(SEM image of Marble); (b) a continuous mineral grain modelled into a discrete unit bond cell.

Fig.3 Application of hydraulic pressure on the newly-created crack facet faces (a) a crack facet created in a unit cell; (b) hydraulic pressure applied on the inner boundary of a unit cell and the induced equivalent nodal force by hydraulic pressure.

Fig.4 Simulation domain (a) geometry and boundary conditions; (b) 'meshing' scheme using triangular element.

Fig.5 Uniaxial tensile stress-strain curve simulated by DVIB with $E=2.16 \mathrm{GPa}$ and $\varepsilon_{t}=3.34 \times 10^{-3}$.

Fig.6 Loading scheme of in-situ stress and fluid pressure.

Fig.7 Distribution of Young's modulus of unit cells (a) Young's modulus distribution of bond cells with different homogenization indexes; (b) Grey image of modulus distribution $(\mathrm{m}=10)$ (Grey bar unit: GPa).

Fig.8 Comparison between (a) the experimental result in Yang et al. (2000) and the simulated multiple fractures with (b) $R=22.7 \mathrm{MPa} / \mathrm{ms}$ and $m=10$ at the time $t=0.506 \mathrm{~ms}$; (c) $R=22.7 \mathrm{MPa} / \mathrm{ms}$ and $m=100$ at the time $t=0.662 \mathrm{~ms}$; (d) $R=45.4 \mathrm{MPa} / \mathrm{ms}$ and $m=10$ at the time $t=0.466 \mathrm{~ms}$; (e) $R=45.4 \mathrm{MPa} / \mathrm{ms}$ and $m=100$ at the time $t=0.412 \mathrm{~ms} .\left(\sigma_{h}=\sigma_{H}=0.0 \mathrm{MPa}\right)$

Fig.9 Correlation between the pressurization rate and the breakdown pressure.

Fig.10 Effect of pressurization rate on fracture branching (a) $R=0.227 \mathrm{MPa} / \mathrm{ms}$ with duration $30.12 \mathrm{~ms}$; (b) $R=2.27 \mathrm{MPa} / \mathrm{ms}$ with duration $4.283 \mathrm{~ms}$; (c) $R=22.7 \mathrm{MPa} / \mathrm{ms}$ with duration $1.2 \mathrm{~ms} ;$ (d) $R=45.4 \mathrm{MPa} / \mathrm{ms}$ with duration $0.9 \mathrm{~ms}$; (e) $R=113.5 \mathrm{MPa} / \mathrm{ms}$ with duration $0.496 \mathrm{~ms}$; (f) $R=227.0 \mathrm{MPa} / \mathrm{ms}$ with duration $0.494 \mathrm{~ms}$. (In-situ stresses: $\sigma_{h}=2.0 \mathrm{MPa}$ and $\left.\sigma_{H}=5.0 \mathrm{MPa}\right)$

Fig.11 Propagation and fracture branching process at the time (a) $t=0.575 \mathrm{~ms}$; (b) $t=0.725 \mathrm{~ms}$; (c) $t=0.9 \mathrm{~ms} ; \quad$ (d) $t=1.1 \mathrm{~ms}$. (Pressurization rate: $R=22.7 \mathrm{MPa} / \mathrm{ms} ;$ In-situ stresses: $\sigma_{h}=2.0 \mathrm{MPa}$ and $\left.\sigma_{H}=5.0 \mathrm{MPa}\right)$

Fig.12 Effects of pressure level on HF (a) $R=22.7 \mathrm{MPa} / \mathrm{ms}, P=7.0 \mathrm{MPa}, t=1.841 \mathrm{~ms}$; (b) $R=135.7 \mathrm{MPa} / \mathrm{ms}, P=7.0 \mathrm{MPa}, t=1.7 \mathrm{~ms} ; \quad$ (c) $R=22.7 \mathrm{MPa} / \mathrm{ms}, \quad P=25.0 \mathrm{MPa}$, $t=1.2 \mathrm{~ms} ; \quad$ (d) $\quad R=135.7 \mathrm{MPa} / \mathrm{ms}, P=25.0 \mathrm{MPa}, \quad t=0.737 \mathrm{~ms} \quad$ (In-situ stresses: $\sigma_{h}=2.0 \mathrm{MPa}$ and $\left.\sigma_{H}=5.0 \mathrm{MPa}\right)$

Fig.13 Critical fracture length of HF with (a) $P=7.0 \mathrm{MPa}, t=1.841 \mathrm{~ms}$; (b) $P=11.0 \mathrm{MPa}$, $t=1.398 \mathrm{~ms} ; \quad$ (c) $P=15.0 \mathrm{MPa}, \quad t=1.249 \mathrm{~ms} ; \quad$ (d) $P=27.0 \mathrm{MPa}, \quad t=1.200 \mathrm{~ms}$ ). ( $R=22.7 \mathrm{MPa} / \mathrm{ms}$, In-situ stress: $\sigma_{h}=2.0 \mathrm{MPa}$ and $\left.\sigma_{H}=5.0 \mathrm{MPa}\right)$

Fig.14 Critical fracture length versus internal fluid pressure with different pressurization rate.

Fig.15 Illustration of the volume increment of hydraulic fracture and wellbore from $t_{i-1}$ to $t_{i}$. 
Fig.16 Injection rate versus time in different cases.

Fig.17 Influence of in-situ stress contrast on HF network distribution (a) $\sigma_{h}=2.0 \mathrm{MPa}$, $\sigma_{H}=2.0 \mathrm{MPa}, \quad t=1.200 \mathrm{~ms} ; \quad(b) \sigma_{h}=2.0 \mathrm{MPa}, \sigma_{H}=5.0 \mathrm{MPa}, t=1.225 \mathrm{~ms} ; \quad$ (c) $\sigma_{h}=2.0 \mathrm{MPa}, \sigma_{H}=8.0 \mathrm{MPa}, t=1.187 \mathrm{~ms}$. ( $\left.P=17.0 \mathrm{MPa}, R=22.7 \mathrm{MPa} / \mathrm{ms}\right)$.

Fig.18 Setup of perforations connecting wellbore.

Fig.19 Influence of perforation inclination on HF (a) $\beta=30^{\circ}, t=2.24 \mathrm{~ms}$; (b) $\beta=45^{\circ}$, $t=2.37 \mathrm{~ms}$; (c) $\beta=60^{\circ}, t=2.69 \mathrm{~ms}$; (d) $\beta=75^{\circ}, t=3.85 \mathrm{~ms}$. (The perforation length is $0.1 \mathrm{~m} ; P=3.5 \mathrm{MPa}, R=22.7 \mathrm{MPa} / \mathrm{ms}, \sigma_{h}=2.0 \mathrm{MPa}$ and $\sigma_{H}=2.5 \mathrm{MPa}$.)

Fig.20 Influence of in-situ stress difference on HF with oriented perforations (a) $\sigma_{h}=2.0 \mathrm{MPa}$, $\sigma_{H}=2.0 \mathrm{MPa}, \quad t=2.44 \mathrm{~ms} ; \quad$ (b) $\sigma_{h}=2.0 \mathrm{MPa}, \sigma_{H}=2.5 \mathrm{MPa}, t=2.37 \mathrm{~ms} ;$ (c) $\sigma_{h}=2.0 \mathrm{MPa}, \sigma_{H}=3.0 \mathrm{MPa}, t=2.31 \mathrm{~ms}$. (Perforation length is $0.1 \mathrm{~m} ; P=3.5 \mathrm{MPa}$; $\left.\beta=45^{\circ}, R=22.7 \mathrm{MPa} / \mathrm{ss}\right)$.

Fig.21 Influence of fluid pressure level on HF with oriented perforations (a) $P=3.5 \mathrm{MPa}$ at the time $t=2.37 \mathrm{~ms}$; (b) $P=6.0 \mathrm{MPa}, t=1.49 \mathrm{~ms}$; (c) $P=8.0 \mathrm{MPa}, t=1.33 \mathrm{~ms}$. (Perforation length: $0.1 \mathrm{~m} ; \sigma_{h}=2.0 \mathrm{MPa}$ and $\sigma_{H}=2.5 \mathrm{MPa} ; \beta=45^{\circ}, R=22.7 \mathrm{MPa} / \mathrm{ms}$ ).

(1)

(1)

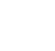

2




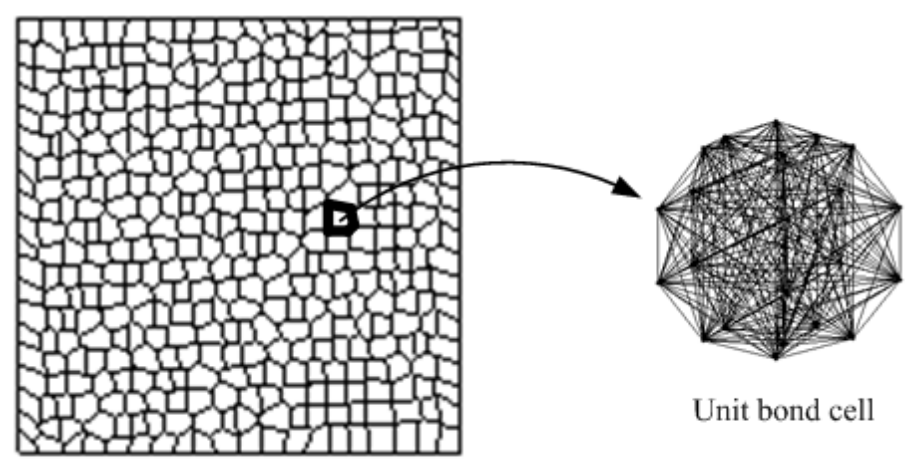

2 Fig.1 Constitution of DVIB discrete structure

3

4

5

6

7
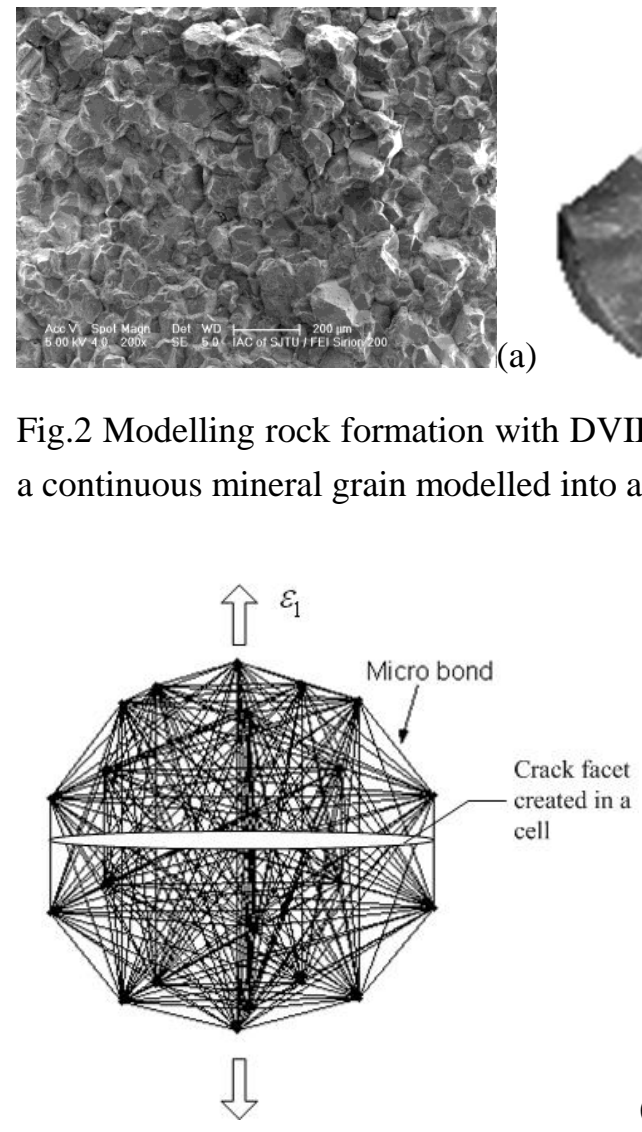

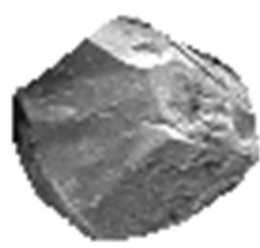

(a)

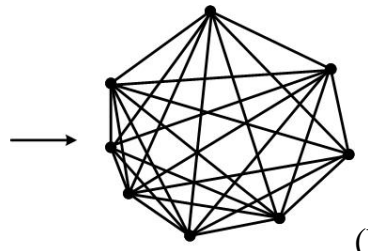

(b)

Fig.2 Modelling rock formation with DVIB (a) mesostructure of rock(SEM image of Marble); (b) a continuous mineral grain modelled into a discrete unit bond cell.

(a)

8

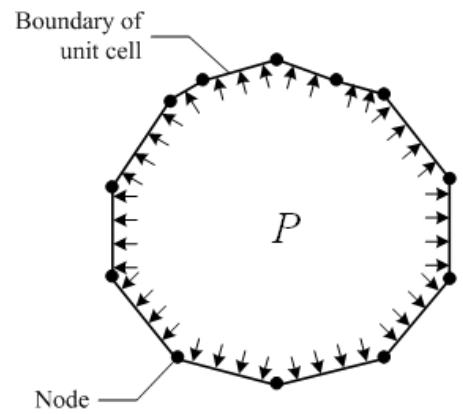

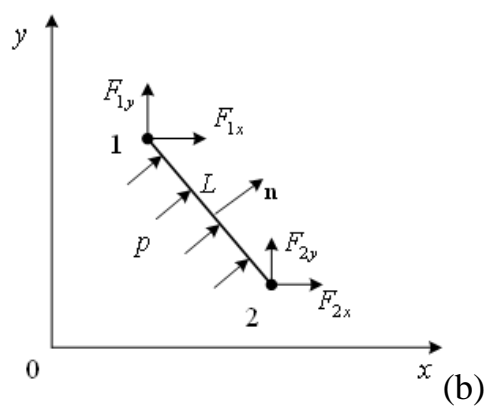

(b)

9 Fig.3 Application of hydraulic pressure on the newly-created crack facet faces (a) a crack facet 10 created in a unit cell; (b) hydraulic pressure applied on the inner boundary of a unit cell and the 11 induced equivalent nodal force by hydraulic pressure. 


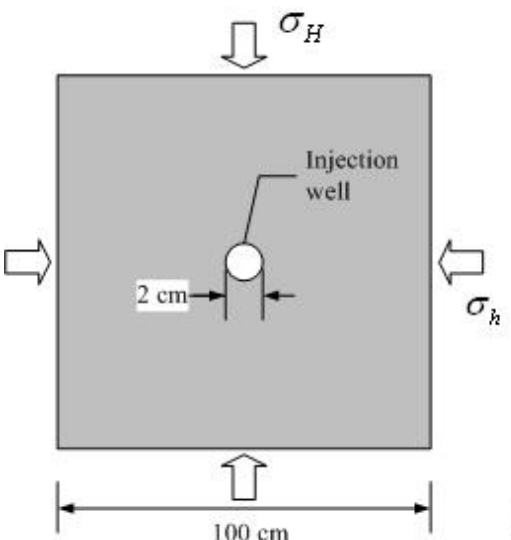

(a)

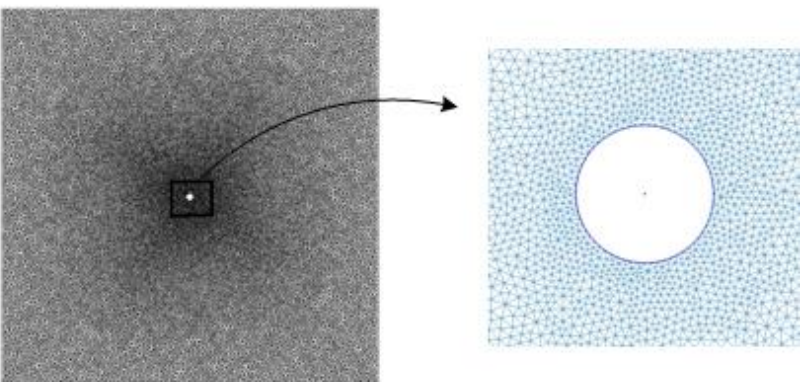

(b)

2 Fig.4 Simulation domain (a) geometry and boundary conditions; (b) 'meshing' scheme using 3 triangular element.

4

5

6 Fig.5 Uniaxial tensile stress-strain curve simulated by DVIB with $E=2.16 \mathrm{GPa}$ and

$7 \quad \varepsilon_{t}=3.34 \times 10^{-3}$.

8

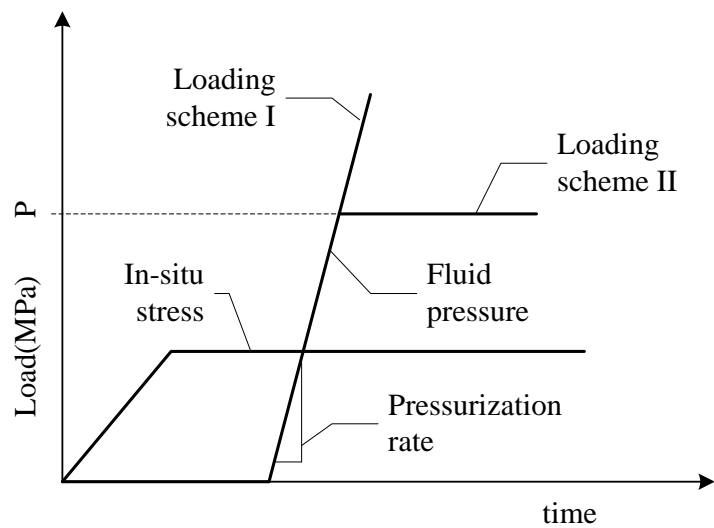

9

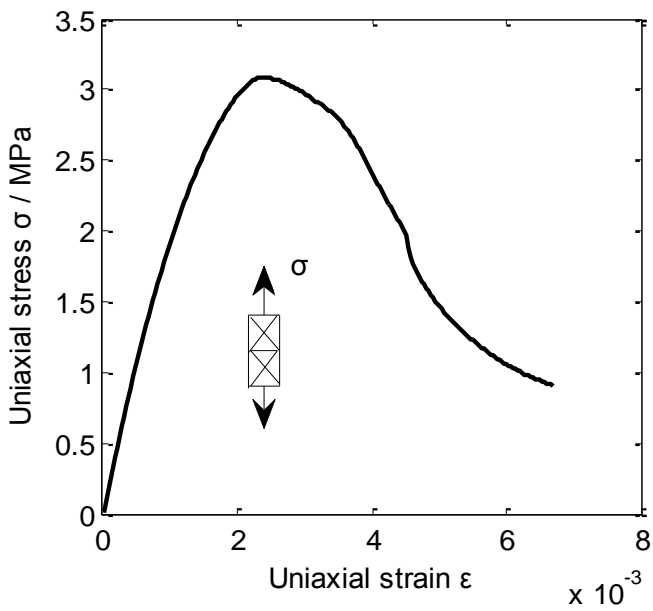

10 Fig.6 Loading scheme of in-situ stress and fluid pressure. 

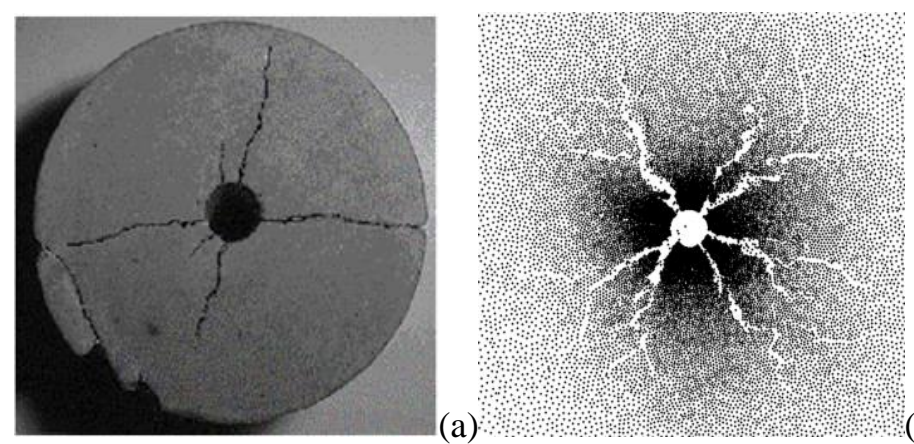

(b)

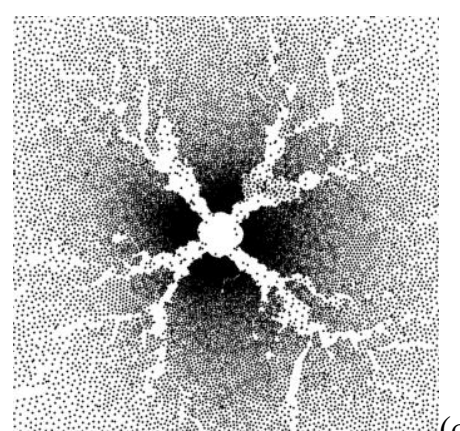

(a)

Fig.7 Distribution of Young's modulus of unit cells (a) Young's modulus distribution of bond cells with different homogenization indexes; (b) Grey image of modulus distribution ( $m=10)$ (Grey bar unit: GPa).
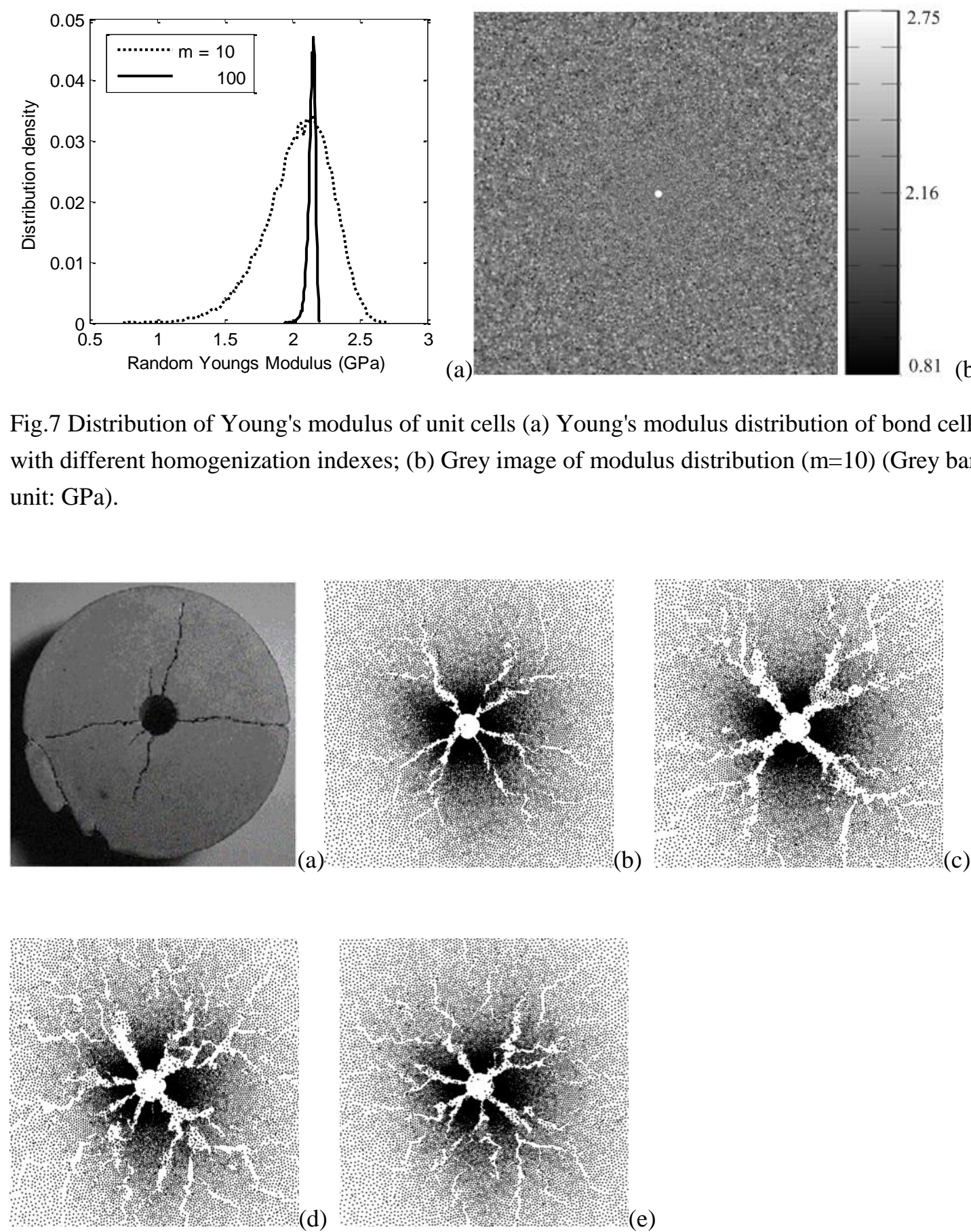

Fig.8 Comparison between (a) the experimental result in Yang et al. (2000) and the simulated multiple fractures with (b) $R=22.7 \mathrm{MPa} / \mathrm{ms}$ and $m=10$ at the time $t=0.506 \mathrm{~ms}$; (c) $R=22.7 \mathrm{MPa} / \mathrm{ms}$ and $m=100$ at the time $t=0.662 \mathrm{~ms}$; (d) $R=45.4 \mathrm{MPa} / \mathrm{ms}$ and $m=10$ at the time $t=0.466 \mathrm{~ms}$; (e) $R=45.4 \mathrm{MPa} / \mathrm{ms}$ and $m=100$ at the time $t=0.412 \mathrm{~ms}$. $\left(\sigma_{h}=\sigma_{H}=0.0 \mathrm{MPa}\right)$ 


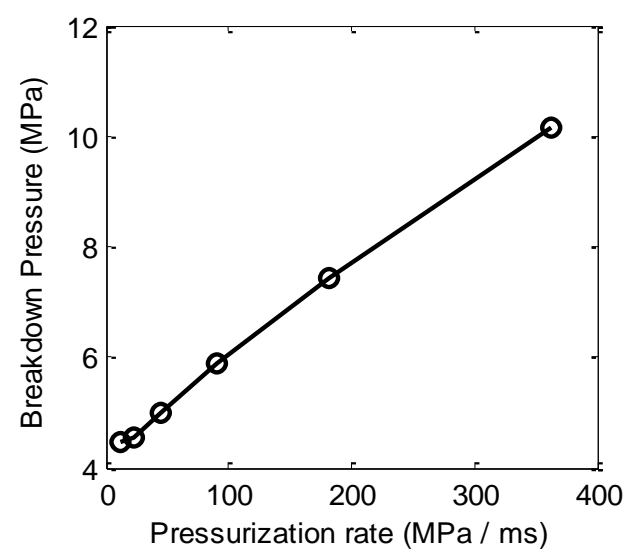

2 Fig.9 Correlation between the pressurization rate and the breakdown pressure.
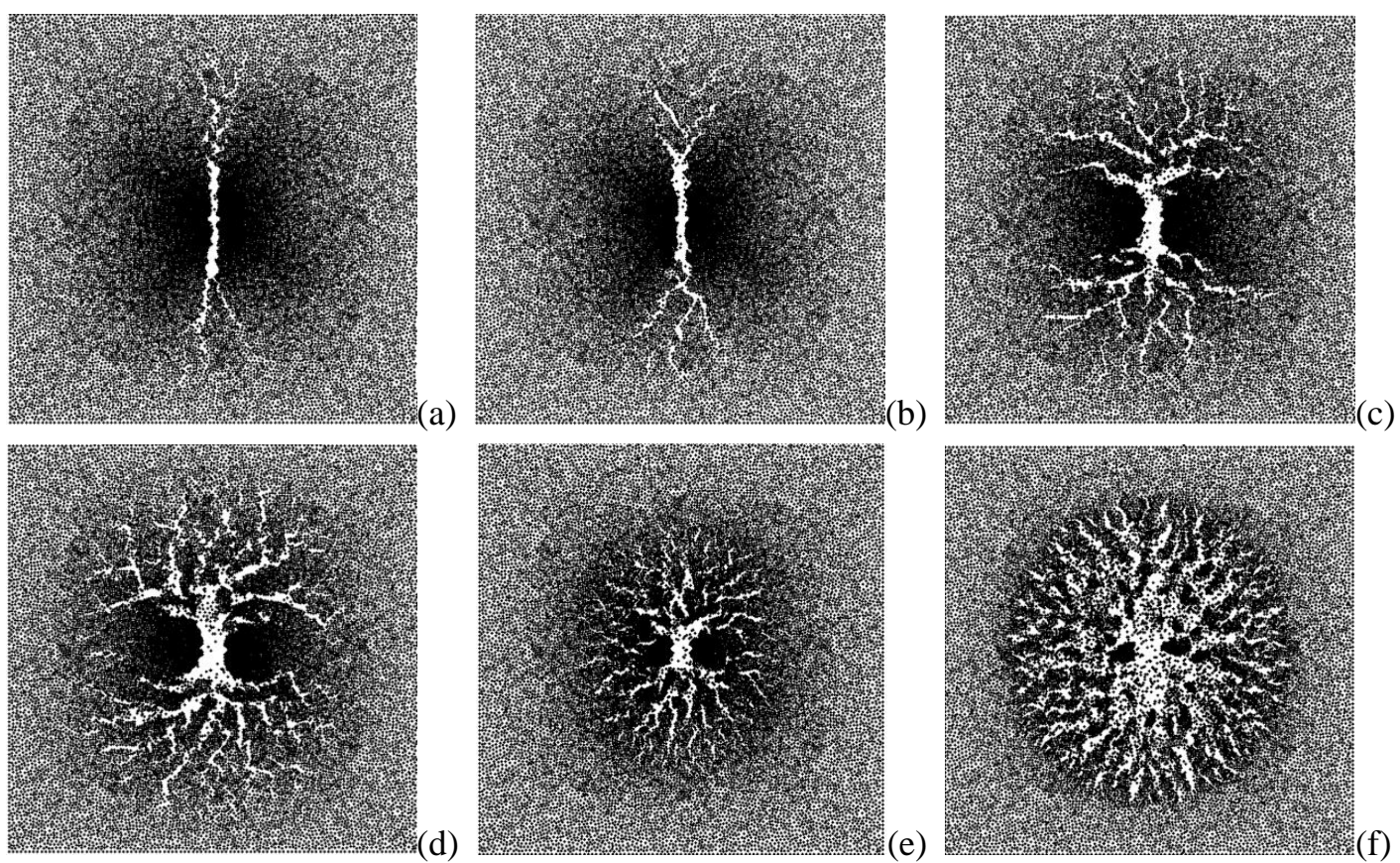

Fig.10 Effect of pressurization rate on fracture branching (a) $R=0.227 \mathrm{MPa} / \mathrm{ms}$ with duration $30.12 \mathrm{~ms}$; (b) $R=2.27 \mathrm{MPa} / \mathrm{ms}$ with duration $4.283 \mathrm{~ms}$; (c) $R=22.7 \mathrm{MPa} / \mathrm{ms}$ with duration $1.2 \mathrm{~ms}$; (d) $R=45.4 \mathrm{MPa} / \mathrm{ms}$ with duration $0.9 \mathrm{~ms}$; (e) $R=113.5 \mathrm{MPa} / \mathrm{ms}$ with duration $0.496 \mathrm{~ms}$; (f) $R=227.0 \mathrm{MPa} / \mathrm{ms}$ with duration $0.494 \mathrm{~ms}$. (In-situ stresses: $\sigma_{h}=2.0 \mathrm{MPa}$ and $\sigma_{H}=5.0 \mathrm{MPa}$ )
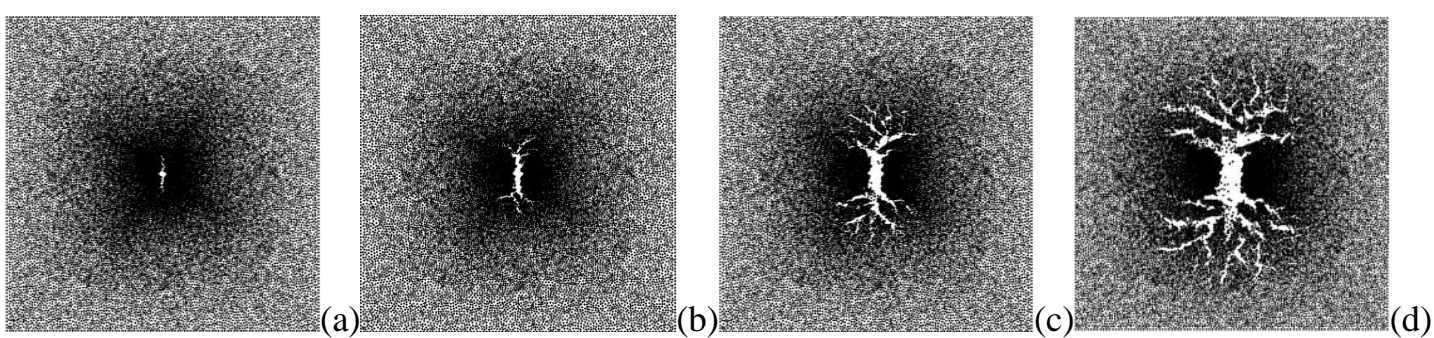

12 Fig.11 Propagation and fracture branching process at the time (a) $t=0.575 \mathrm{~ms}$; (b) $t=0.725 \mathrm{~ms}$; (c) $t=0.9 \mathrm{~ms} ; \quad$ (d) $t=1.1 \mathrm{~ms}$. (Pressurization rate: $R=22.7 \mathrm{MPa} / \mathrm{ms} ; \quad$ In-situ 14 stresses: $\sigma_{h}=2.0 \mathrm{MPa}$ and $\left.\sigma_{H}=5.0 \mathrm{MPa}\right)$ 

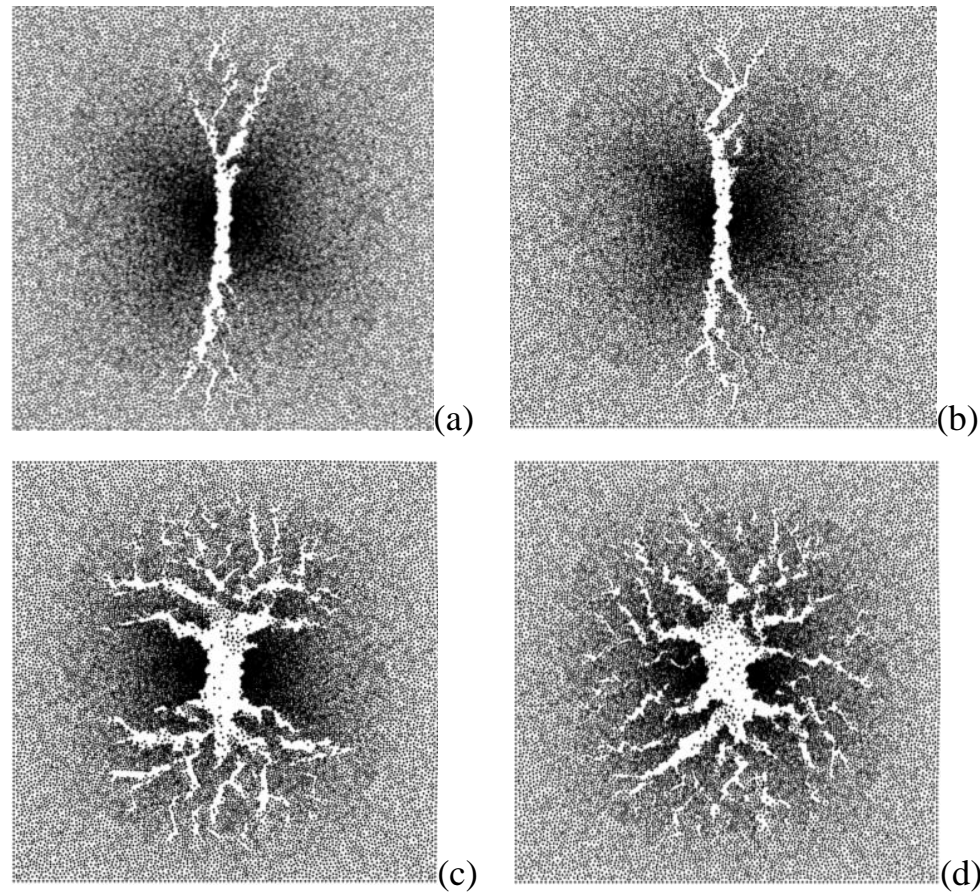

3

Fig.12 Effects of pressure level on HF (a) $R=22.7 \mathrm{MPa} / \mathrm{ms}, P=7.0 \mathrm{MPa}, t=1.841 \mathrm{~ms}$; (b) $4 \quad R=135.7 \mathrm{MPa} / \mathrm{ms}, P=7.0 \mathrm{MPa}, t=1.7 \mathrm{~ms}$; (c) $R=22.7 \mathrm{MPa} / \mathrm{ms}, \quad P=25.0 \mathrm{MPa}, t=1.2 \mathrm{~ms}$; (d) $5 \quad R=135.7 \mathrm{MPa} / \mathrm{ms}, \quad P=25.0 \mathrm{MPa}, \quad t=0.737 \mathrm{~ms} \quad$ (In-situ stresses: $\sigma_{h}=2.0 \mathrm{MPa}$ 6 and $\left.\sigma_{H}=5.0 \mathrm{MPa}\right)$

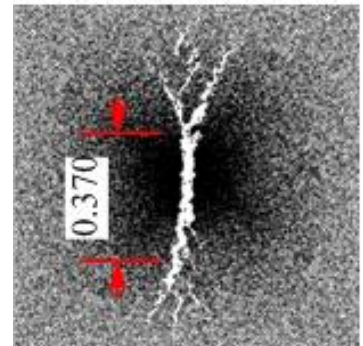

(a)

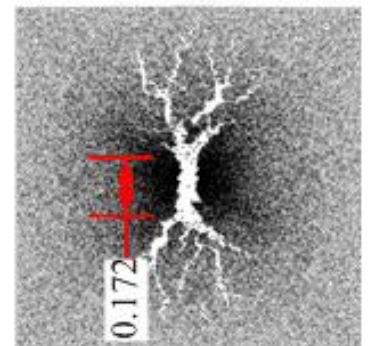

(b)

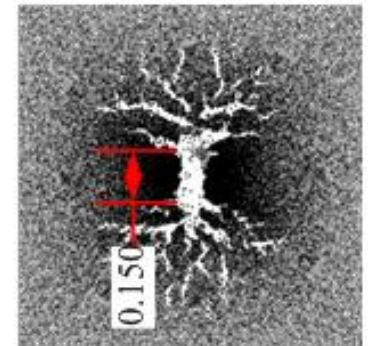

(c)

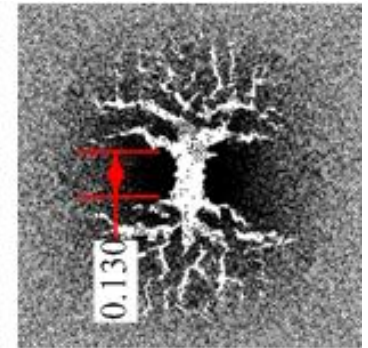

(d)

10 Fig.13 Critical fracture length of $\mathrm{HF}$ with (a) $P=7.0 \mathrm{MPa}, t=1.841 \mathrm{~ms}$; (b) $P=11.0 \mathrm{MPa}$, $11 t=1.398 \mathrm{~ms}$; (c) $P=15.0 \mathrm{MPa}, t=1.249 \mathrm{~ms}$; (d) $P=27.0 \mathrm{MPa}, t=1.200 \mathrm{~ms})$. $(R=22.7 \mathrm{MPa} / \mathrm{ms}$, 12 In-situ stress: $\sigma_{h}=2.0 \mathrm{MPa}$ and $\sigma_{H}=5.0 \mathrm{MPa}$ ) 


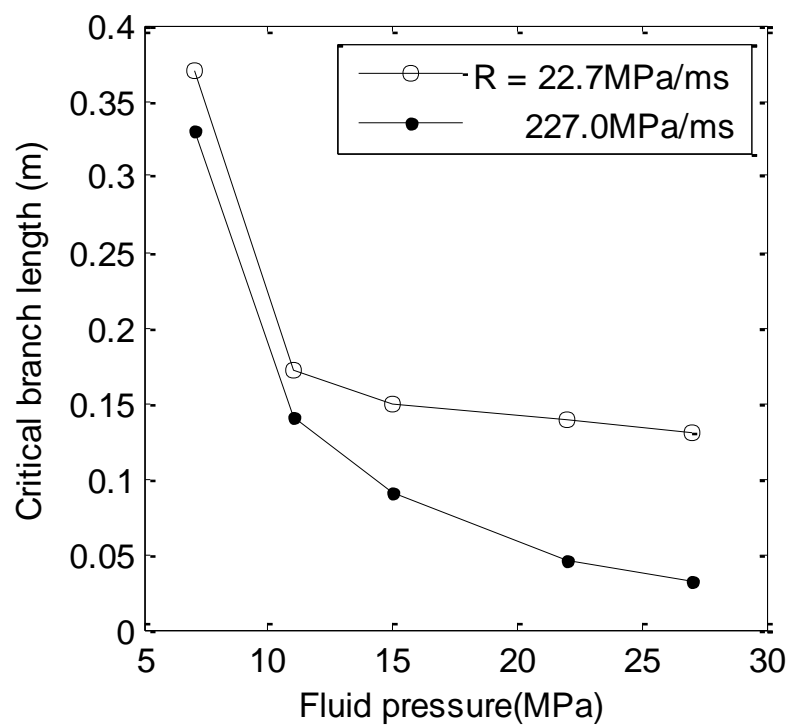

2 Fig.14 Critical fracture length versus internal fluid pressure with different pressurization rate. 3

4

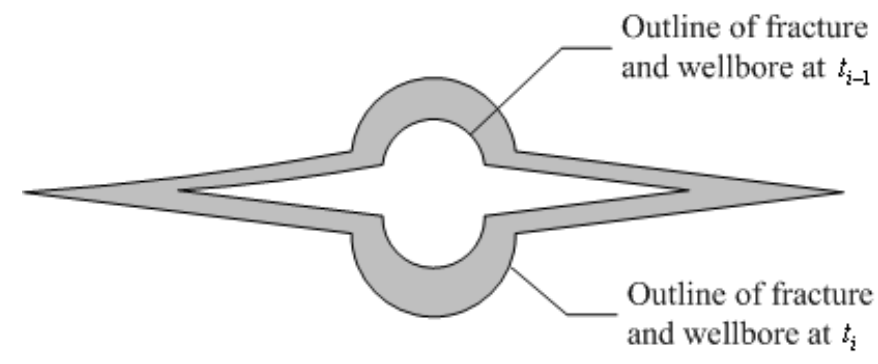

Fig.15 Illustration of the volume increment of hydraulic fracture and wellbore from $t_{i-1}$ to $t_{i}$.

6

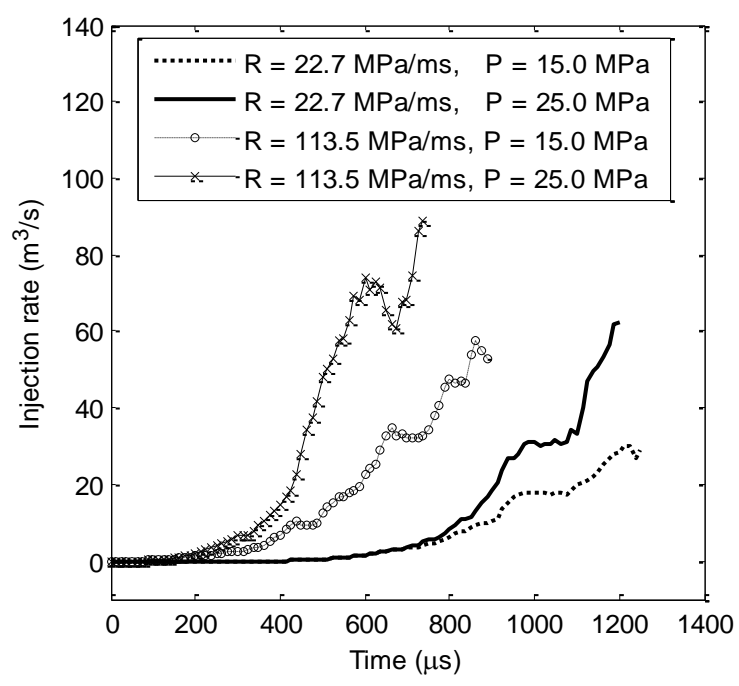

8 Fig.16 Injection rate versus time in different cases. 

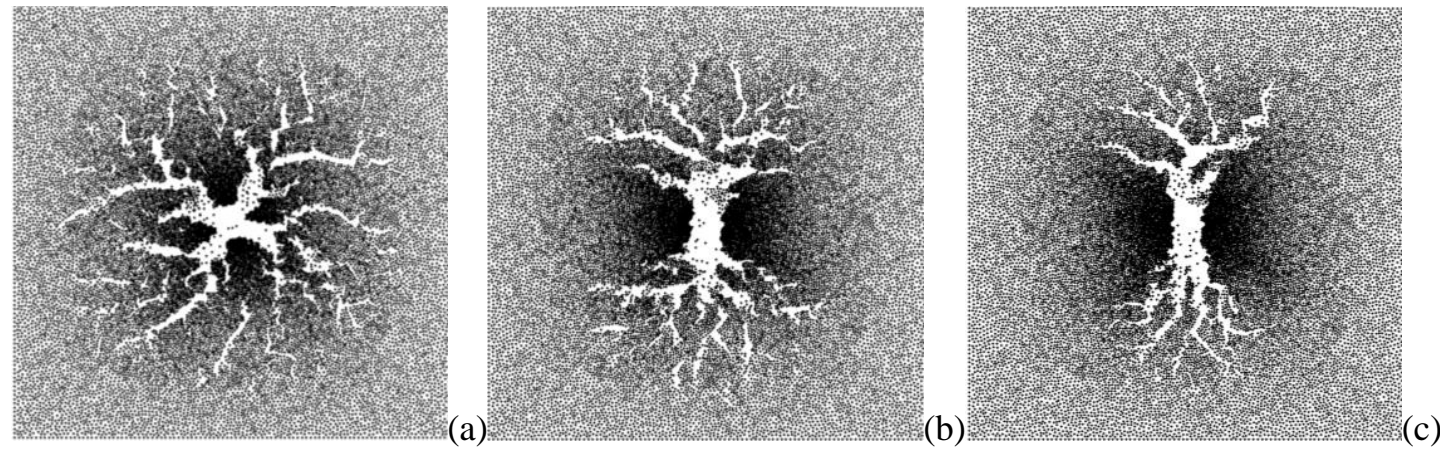
.

Fig.17 Influence of in-situ stress contrast on HF network distribution (a) $\sigma_{h}=2.0 \mathrm{MPa}$, $\sigma_{H}=2.0 \mathrm{MPa}, \quad t=1.200 \mathrm{~ms} ; \quad$ (b) $\sigma_{h}=2.0 \mathrm{MPa}, \quad \sigma_{H}=5.0 \mathrm{MPa}, t=1.225 \mathrm{~ms} ; \quad$ (c) $\sigma_{h}=2.0 \mathrm{MPa}, \sigma_{H}=8.0 \mathrm{MPa}, t=1.187 \mathrm{~ms}$. $(P=17.0 \mathrm{MPa}, R=22.7 \mathrm{MPa} / \mathrm{ms})$.

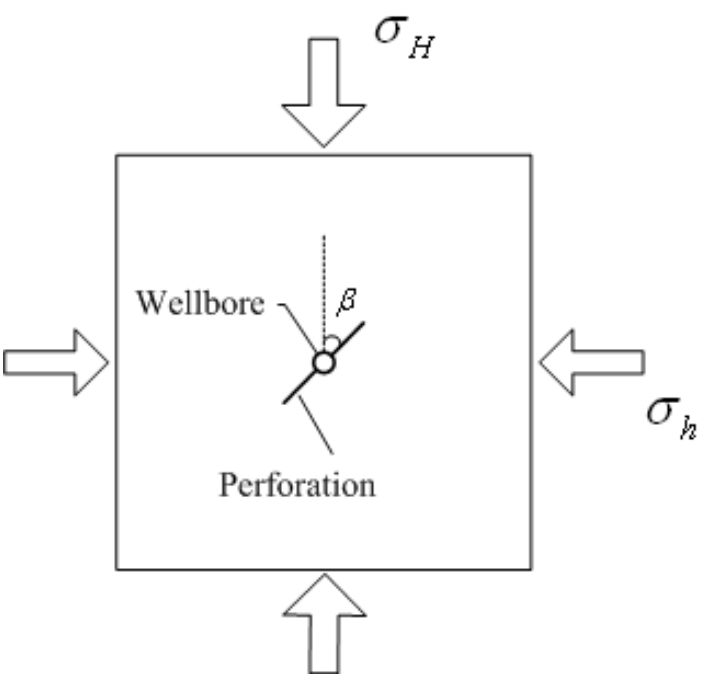

Fig.18 Setup of perforations connecting wellbore.
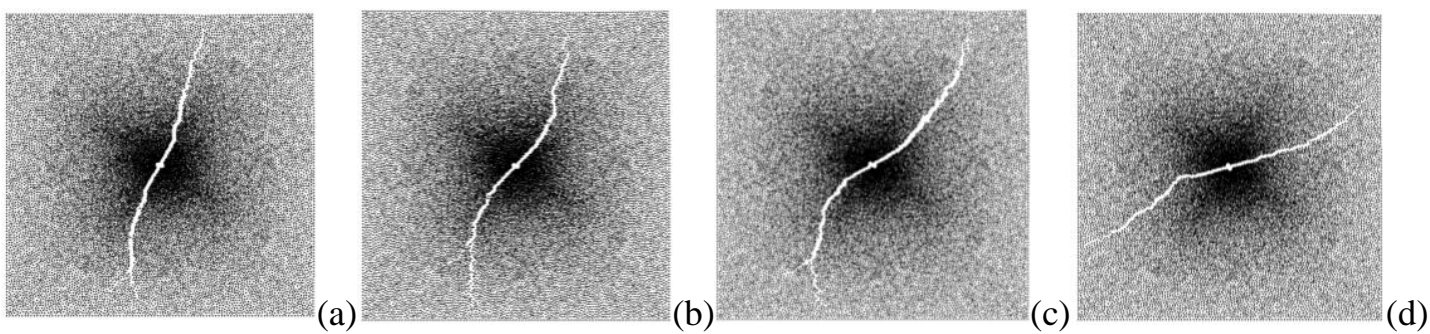

Fig. 19 Influence of perforation inclination on HF (a) $\beta=30^{\circ}, t=2.24 \mathrm{~ms}$; (b) $\beta=45^{\circ}$, $t=2.37 \mathrm{~ms}$; (c) $\beta=60^{\circ}, t=2.69 \mathrm{~ms}$; (d) $\beta=75^{\circ}, t=3.85 \mathrm{~ms}$. (The perforation length is $0.1 \mathrm{~m} ; P=3.5 \mathrm{MPa}, R=22.7 \mathrm{MPa} / \mathrm{ms}, \sigma_{h}=2.0 \mathrm{MPa}$ and $\sigma_{H}=2.5 \mathrm{MPa}$.)

(1)

(1)
9 

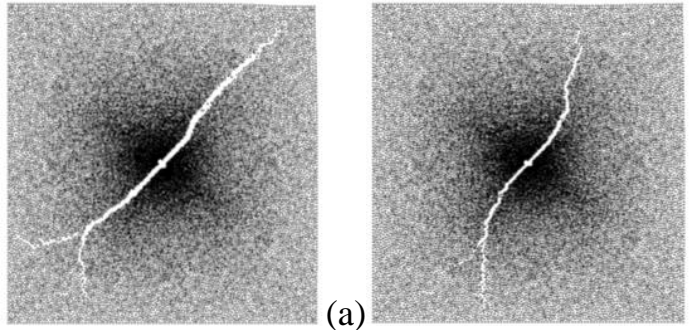

(b)

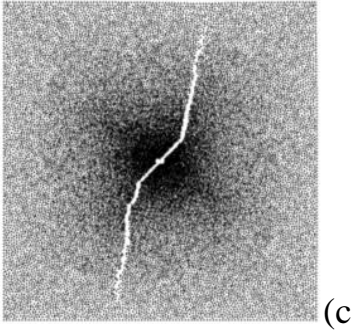

2 Fig.20 Influence of in-situ stress difference on HF with oriented perforations (a) $\sigma_{h}=2.0 \mathrm{MPa}$, $3 \sigma_{H}=2.0 \mathrm{MPa}, \quad t=2.44 \mathrm{~ms} ; \quad(\mathrm{b}) \quad \sigma_{h}=2.0 \mathrm{MPa}, \sigma_{H}=2.5 \mathrm{MPa}, \quad t=2.37 \mathrm{~ms} ; \quad$ (c) $4 \sigma_{h}=2.0 \mathrm{MPa}, \sigma_{H}=3.0 \mathrm{MPa}, t=2.31 \mathrm{~ms}$. (Perforation length is $0.1 \mathrm{~m} ; P=3.5 \mathrm{MPa} ; \beta=45^{\circ}$, $5 \quad R=22.7 \mathrm{MPa} / \mathrm{ss})$.
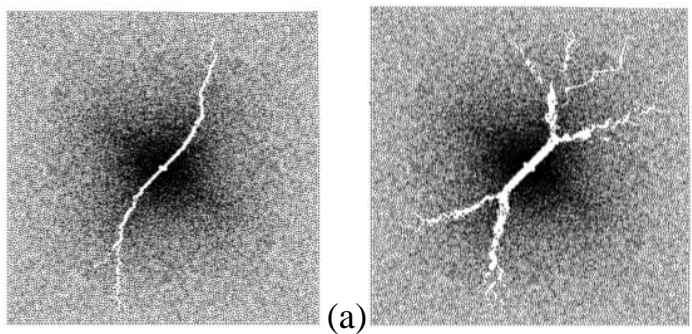

(b)

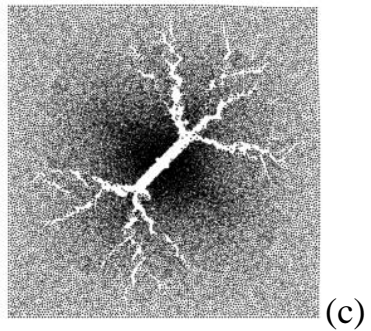

Fig.21 Influence of fluid pressure level on HF with oriented perforations (a) $P=3.5 \mathrm{MPa}$ at the time $t=2.37 \mathrm{~ms}$; (b) $P=6.0 \mathrm{MPa}, t=1.49 \mathrm{~ms} ;$ (c) $P=8.0 \mathrm{MPa}, t=1.33 \mathrm{~ms}$. (Perforation length: $0.1 \mathrm{~m} ; \sigma_{h}=2.0 \mathrm{MPa}$ and $\left.\sigma_{H}=2.5 \mathrm{MPa} ; \beta=45^{\circ}, R=22.7 \mathrm{MPa} / \mathrm{ms}\right)$. 